\title{
Expression levels of specific microRNAs are increased after exercise and are associated with cognitive improvement in Parkinson's disease
}

\author{
FRANCIELE CASCAES DA SILVA ${ }^{1}$, MICHELE PATRÍCIA RODE ${ }^{2}$, GIOVANNA GRUNEWALD VIETTA ${ }^{3}$, \\ RODRIGO DA ROSA IOP ${ }^{1}$, TÂNIA BEATRIZ CRECZYNSKI-PASA ${ }^{2}$, \\ ALESSANDRA SWAROWSKY MARTIN ${ }^{4}$ and RUDNEY DA SILVA ${ }^{1}$
}

\begin{abstract}
${ }^{1}$ Center for Health Sciences and Sports, Adapted Physical Activity Laboratory, Santa Catarina State University, Florianópolis, Santa Catarina 88080-350; ${ }^{2}$ Pharmaceutical Sciences Department, Federal University of Santa Catarina, Florianópolis, Santa Catarina 88010-970; ${ }^{3}$ Nucleus of Epidemiology, University of Southern Santa Catarina, Palhoça, Santa Catarina 88137-270; ${ }^{4}$ Center for Health and Sport Sciences, Physical Therapy Department, Santa Catarina State University, Florianópolis, Santa Catarina 88080-350, Brazil
\end{abstract}

Received February 21, 2020; Accepted December 2, 2020

DOI: $10.3892 / \mathrm{mmr} .2021 .12257$

\begin{abstract}
There is a consensus regarding the efficacy of physical exercise in maintaining or improving human health; however, there are few studies examining the effect of physical exercise on the expression levels of microRNAs (miRNA/miRs) in Parkinson's disease (PD). The aim of the present study was to investigate the effects of an interval training program on a cycle ergometer on the expression levels of miR-106a-5p, miR-103a-3p and miR-29a-3p in serum samples from men with PD. This was a quasi-experimental study with pre- and post-testing and with a non-equivalent group design. The participants were selected based on the eligibility criteria and subsequently classified into two groups: Experimental group and control group. The evaluations were performed at the beginning of the study (week 0) and after 8 weeks of the intervention program (week 9). The interval training program was performed on a cycle ergometer for $30 \mathrm{~min}$, three times a week during an 8-week period. The expression levels of miR-106a-5p, miR-103a-3p and miR-29a-3p in the experimental group were increased after physical exercise and were associated with cognitive improvement in men with PD. However, further studies are required to clarify the potential use of these circulating miRNAs as markers of adaptation to physical exercise. Collectively, the present results indicated that these three miRNAs may be
\end{abstract}

Correspondence to: Dr Franciele Cascaes Da Silva, Center for Health Sciences and Sports, Adapted Physical Activity Laboratory, Santa Catarina State University, 358 Pascoal Simone Street, Coqueiros, Florianopolis, Santa Catarina 88080-350, Brazil

E-mail: francascaes@yahoo.com.br

Key words: physical exercise, microRNA, serum, Parkinson's disease associated with the exercise response and cognitive improvement in men with PD.

\section{Introduction}

In recent years, there has been a consensus that physical exercise is effective in maintaining or improving cardiovascular and musculoskeletal health, both of which are fundamental for the preservation of physiological functioning and independence (1). Previous studies have reported that some physical exercise modalities are effective in reducing falls (2-4), and in improving balance (2) and symptoms of anxiety and depression $(5,6)$ in healthy individuals.

There has been increasing evidence of the benefits of physical exercise in improving mobility (7-10), postural stability (7-10), gait $(11,12)$, quality of life $(13,14)$, cognitive function (13-15) and severity of symptoms in individuals with Parkinson's disease (PD) (10). PD has a lifetime risk of $2 \%$ and is considered the second most common neurodegenerative disorder (16). Functional disability caused by PD leads to an increased inability to perform activities of daily living, loss of independence, decreased quality of life, and socioeconomic and occupational losses (17). Motor deficiencies in individuals with PD, caused by bradykinesia, rigidity, tremor and postural instability, accelerate the declines in functional capacity, especially when associated with decreasing physical activity and a sedentary lifestyle $(18,19)$.

Recent advances in understanding the molecular mechanisms of PD have revealed the involvement of small non-coding RNA molecules, known as microRNAs (miRNAs/miRs), in the derangements and perturbation of processes associated with the regulation of the expression levels of genes involved in PD development (20-22). Moreover, a systematic review of the literature identified $\sim 91$ different miRNAs associated with $\mathrm{PD}$, with the expression levels of 39 of these miRNAs differing significantly between individuals with PD and healthy controls and/or between treated and untreated patients with PD (23), such 
as miR-30b, miR-30c, miR-26a, miR-450b-3p, miR-148b, miR-1, miR-22*, miR-29a, miR-103a-3p, miR-30b-5p, miR-29a-3p, miR-1249, miR-20a, miR-18b, miR-378c, miR-4293, miR-652, miR-15a*, miR-29c, miR-376c, miR-143, and miR-19b (downregulated miRNAs) and miR-1826, miR-626, miR-505, miR-16-2a*, miR-26a2*, miR-30a, miR-7, miR-9-3-p, miR-9-5p, miR-129, miR-132, miR-423, miR-365, miR-486, miR-1260, miR-218 and miR-331-5p (upregulated miRNAs).

A systematic review of experimental and quasi-experimental studies published between 2007 and 2017 (24) revealed the acute and/or chronic effects of physical exercise (aerobic and resistance) on the expression of several miRNAs in healthy individuals (25-36), athletes (37-40), young and older adults (41-50), as well as in patients with chronic heart failure (CHF) $(51,52)$, chronic kidney disease (CKD) (53), type 2 diabetes mellitus (DM2) associated with morbid obesity (54), prediabetes (55) and intermittent claudication $(56,57)$. However, to the best of our knowledge, there have been no studies investigating the effects of physical exercise on the expression levels of miRNAs in individuals with PD. Therefore, additional studies should be performed to examine the effect of physical exercise on circulating miRNAs in individuals with pathological conditions, such as neurological diseases, as physical exercise serves an important role in mitigating or delaying the emergence of symptoms, which ultimately results in a certain degree of independence and improved quality of life, indicating its consideration as an auxiliary method in traditional therapies (24).

Based on these premises, the present study aimed to investigate the effects of an interval training program using a cycle ergometer on the expression levels of miRs associated with PD, including miR-106a-5p, miR-103a-3p and miR-29a-3p, in serum samples from men with PD.

\section{Materials and methods}

Ethics approval and consent. This quasi-experimental study with pre- and post-tests, and with a non-equivalent group design was approved by the Ethics Committee for Research involving Human Beings of the State University of Santa Catarina in 2015 (certificate of presentation for ethical appreciation no. 50032415.1.0000.0118). The objectives of this study and the procedures adopted throughout the research were explained to all participants, who voluntarily agreed to continue participation by signing an informed consent document.

Study design. The evaluations were performed at the beginning of the study (week 0) and after 8 weeks of the intervention program (week 9) at the Center for Health and Sports Sciences (CEFID; Florianópolis, Brazil) from March to June 2018.

Identification, selection and allocation of participants. A total of eight men with PD participated in this study. The participants fulfilled the following inclusion criteria: i) Age $\geq 50$ years old and $\leq 80$ years old; ii) classification in stages I, II and III of the Hoehn \& Yahr scale; iii) a score $\geq 24$ in the Mini-Mental State Examination (MMSE); iv) use of stable medication during the last 3 months; and v) physical ability to walk $300 \mathrm{~m}$ or more during the 6 -min walk test (6MWT). The decision to include only men in this study was made given the need to minimize possible sex-specific confounding effects, such as those arising from typical hormonal implications of the menstrual cycle in women, which may cause changes in circulating miRNA expression levels $(58,59)$.

During the recruitment phase, some individuals indicated that they would meet the inclusion criteria. After the initial assessments, these potential participants were excluded as they may i) have a deep brain stimulator implant; ii) present with other neurological disorders, musculoskeletal diseases and uncontrolled hypertension; iii) show changes in cognitive functions that would impair cooperation and comprehension of the proposed activities; and iv) have visual deficits.

The participants were selected based on the eligibility criteria and classified into two groups (both $n=8$ ): Experimental group (EG, interval training program) and control group (CG). The medications prescribed [levodopa (L-dopa) or Prolopa] for the participants were not changed by the researchers during the present study. All evaluations and training sessions were performed at the same time of day to minimize the effects of scheduled medication on motor function.

Demographic, economic and clinical assessments. Demographic and economic information was collected using a clinical report form specifically developed for this study in March 2018. Clinical characteristics, namely time of diagnosis, disease severity and motor function were respectively assessed using a clinical report form, the modified Hoehn \& Yahr Scale (60), with scores ranging from 0 (no signs of disease) to 5 (wheelchair bound or bedridden unless aided), and the Unified Parkinson's Rating Scale-section III (UPDRS) (61), where the score of each of the 14 items ranges from 0-4 and higher values indicate greater impairment.

Overall cognition was assessed through the MMSE (62), with a score ranging from 0-30 points and lower scores indicating a possible cognitive deficit, and the Montreal Cognitive Assessment (MoCA) (63), with a total score of 30 points and scores $\geq 26$ indicating absence of cognitive impairment.

Cardiorespiratory performance was assessed in field tests, and all participants were submitted to the 6MWT following the Brazilian guidelines for the application of the test (64). The $6 \mathrm{MWT}$ is useful to evaluate clinical data and to help design rehabilitation therapies for individuals with PD (65).

Blood samples. Blood was collected following the recommendations of the Brazilian Society of Clinical Pathology/Laboratory Medicine for venous blood collection (66). All participants had their blood samples collected in the afternoon (week 0 and 9). Peripheral blood samples $(5 \mathrm{ml})$ were collected in Vacutainer tubes without anticoagulant (BD Biosciences). The samples were processed for serum isolation within $2 \mathrm{~h}$ of collection. Serum samples were centrifuged at 3,000 x $\mathrm{g}$ for $10 \mathrm{~min}$ at $4^{\circ} \mathrm{C}\left(\mathrm{Omega}{ }^{\circledR}\right.$ centrifuge). The serum was divided into aliquots and stored in a freezer at $-80^{\circ} \mathrm{C}$ for subsequent analyses, which were performed by the Group of Studies on Micro-Macromolecule Interactions of the Federal University of Santa Catarina. The aliquots were transported by land on dry ice following the Brazilian Health Regulatory Agency guidelines for blood transport and components (67). Serum samples with hemolysis were not included in the study. 
Extraction of total $R N A$ and reverse transcription-quantitative $P C R$. Total RNA was extracted using the mirVana ${ }^{\text {TM }}$ PARIS $^{\text {TM }}$ RNA kit (Thermo Fisher Scientific, Inc.) according to the manufacturer's instructions. During RNA extraction, $25 \mathrm{fmol}$ spike-in cel-miR-238-3p from Caenorhabditis elegans was added to each serum sample after denaturation. To evaluate the amount and quality of total RNA, the NanoVue Plus spectrophotometer (GE Healthcare Life Sciences) was used. Finally, the total RNA obtained was stored in a freezer at $-80^{\circ} \mathrm{C}$.

For qPCR, polyadenylation, RT and qPCR were performed using the miRNA RT-qPCR Master Mix Detection kit (Agilent Technologies, Inc.) according to the manufacturer's instructions. For the qPCR experiment, the specific primers of each miRNA were designed following the recommendations of the miRNA RT-qPCR Master Mix Detection kit protocol (Agilent Technologies, Inc.). Primers were designed for evaluation of the expression levels of the following miRNAs: Cel-miR-238-3p, hsa-miR-106a-5p, hsa-miR-103a-3p and hsa-miR-29a-5p. The sequences of the primers are presented in Table SI. The efficiency of the primers was determined using LinRegPCR version 2018.0 (68).

The qPCR data were analyzed on 96-well plates using the StepOnePlus ${ }^{\text {TM }}$ Real-Time PCR System (Applied Biosystems; Thermo Fisher Scientific, Inc.). The qPCR reactions were performed in a final volume of $25 \mu \mathrm{l}$ according to the manufacturer's instructions. The qPCR experimental conditions were as follows: Initial denaturation at $95^{\circ} \mathrm{C}$ for $10 \mathrm{~min}$, followed by 40 cycles at $95^{\circ} \mathrm{C}$ for $10 \mathrm{sec}, 53^{\circ} \mathrm{C}$ for $15 \mathrm{sec}$ and $72^{\circ} \mathrm{C}$ for $20 \mathrm{sec}$. Finally, the specificity of the reactions was evaluated via analysis of dissociation curves $\left(95^{\circ} \mathrm{C}\right.$ for $1 \mathrm{~min}$, $53^{\circ} \mathrm{C}$ for $30 \mathrm{sec}$, annealing temperature up to $95^{\circ} \mathrm{C}$ with ramp of $0.3^{\circ} \mathrm{C}$ per second and $95^{\circ} \mathrm{C}$ for $1 \mathrm{~min}$ ). The miRNA with $\mathrm{Cq}$ value $>35$ was considered undetected. The reactions were performed in triplicate, assuming the geometric mean between the $\mathrm{Cq}$ values found for each sample to calculate relative gene expression. For the calculation of relative gene expression, the $2^{-\Delta \Delta \mathrm{Cq}}$ method described by Livak and Schmittgen was used (69).

Prediction of target genes. Prediction analyses of target genes of miR-106a-5p, -103a-3p and $-29 a-3 p$ were performed using two databases (TargetScan version 7.2: http://www. targetscan.org/vert_72/ and miRDB January 2019 version: http://www.mirdb.org/) (70,71). The final list of target genes was obtained through the intersection of the results from the two databases. The analysis of the main biological processes $(\mathrm{P}<0.05)$ involved in the target genes list was performed using the Gene Ontology (GO) database (Released 2018-12-01; http://geneontology.org/) (72). The most relevant biological processes were visualized using REViGO (version 2017; revigo.irb.hr/) (73).

Interval training program. The interval training program was performed on a cycle ergometer (Embreex ${ }^{\circledR}$ stationary bicycle; Embreex) for $30 \mathrm{~min}$, three times a week during an 8 -week period. The program was supervised by a physiotherapist specialized in Exercise Physiology and Customized Training for Special Groups. All activities were performed at the CEFID. The exercise sessions were standardized and divided into five parts: i) Initial part (prior to training): Blood pressure (BP), heart rate (HR) and rate of perceived exertion (RPE) were measured; ii) Preparation/warm-up (5 min): Participants were instructed to pedal at a comfortable rate; iii) Training (20 min): Participants were asked to pedal for $15 \mathrm{sec}$ at an intensity corresponding to $80 \% \mathrm{HR}_{6 \mathrm{MWT}}$ (74). Due to cardiovascular adjustments in the first sec of the training, perceived exertion was controlled during the stimulus phase according to the RPE scale 6-7 (74). In the recovery phase, the participants were recommended to pedal for $45 \mathrm{sec}$ at an intensity of $55-60 \% \mathrm{HR}_{6 \mathrm{MWT}}$, which corresponds to the RPE scale 2-3. Thus, the participants performed the interval training composed of 20 stimuli of $15 \mathrm{sec}$ and recovery of $45 \mathrm{sec}$ (74). The HR was monitored throughout the training using an FT1 Polar ${ }^{\circledR}$ heart rate monitor (74). Sound signals indicated the moment when the participant should change the pedaling intensity.

iv) Cooling-off/calm down (5 min): Participants were instructed to pedal at a comfortable rate; and v) Final part (similar to the initial part): BP, HR and RPE were measured.

Each participant was monitored on a daily basis using a control chart including the participant's name, date of activity, $\mathrm{BP}, \mathrm{HR}$, initial and final perceived exertion rates. In addition, $\mathrm{HR}$ and perceived exertion were recorded at 15 and $45 \mathrm{sec}$ of each $\min$ for $20 \mathrm{~min}$.

Statistical analysis. The data were initially entered into a Microsoft Excel ${ }^{\circledR}$ spreadsheet (2010; Microsoft Corporation) and were subsequently exported to the IBM $^{\circledR}$ SPSS program (version 20.0; IBM Corp.) and to the GraphPad Prism 6 statistics software (GraphPad Software, Inc.). Data are presented as the mean $\pm \mathrm{SD}$ of two independent experimental repeats. The normality of the data was analyzed using the Shapiro-Wilk test. The t-test for independent samples was used to compare the groups (EG and CG). Comparisons among the participants before (week 0) and after (week 9) the intervention were conducted using the t-test for paired samples with GraphPad Prism 6 statistics software. The correlation between the variables UPDRS, MMSE, MoCA, 6MWT and the relative expression levels of the miRNAs (before and after training) were evaluated using the Spearman's rank correlation coefficient. $\mathrm{P}<0.05$ was considered to indicate a statistically significant difference.

\section{Results}

Participant characteristics. After the research was advertised on social media, nine assessed individuals met the eligibility criteria to participate in the study. However, between the assessment phase and the beginning of the exercise program, one individual decided to withdraw participation due to personal reasons. Demographic and economic data, clinical characteristics, global cognition and cardiorespiratory performance at baseline are summarized in Table I.

Relative expression of miRNAs before and after cycling training program. There was no difference in the relative expression levels of the miRNAs analyzed between the EG and CG before and after the cycling training program. Regarding 
Table I. Characteristics of the study participants at baseline $(n=8)$.

\begin{tabular}{lccr}
\hline & \multicolumn{2}{c}{ Groups } & P-value \\
\cline { 2 - 3 } Characteristics & EG (n=4) & CG (n=4) & 0.745 \\
\hline Demographic and economic data & & & 0.843 \\
Age, years & $66.25 \pm 12.97$ & $63.50 \pm 9.60$ & 0.752 \\
Years of schooling & $11.00 \pm 2.16$ & $10.25 \pm 6.94$ & 0.344 \\
ABEP, points & $26.50 \pm 7.41$ & $29.25 \pm 14.86$ & - \\
Clinical characteristics & & & - \\
$\quad$ Time of diagnosis, years & $5.75 \pm 3.68$ & $9.25 \pm 5.73$ & - \\
Hoehn \& Yahr scale & $3(75)$ & $3(75)$ & 0.069 \\
Stage I & $1(25)$ & $1(25)$ & 0.651 \\
Stage II & 0 & $8.50 \pm 2.51$ & 0.513 \\
Stage III & $12.50 \pm 2.38$ & $26.75 \pm 2.63$ & 0.060 \\
UPDRS- section III & & $23 \pm 5.47$ & \\
Global cognition & $27.50 \pm 1.73$ & $546.79 \pm 74.99$ & \\
MMSE & $25.50 \pm 4.65$ & & \\
MoCA & & & \\
Cardiorespiratory performance & $22.00 \pm 84.36$ & & \\
Distance in 6MWT, m & & & \\
\hline
\end{tabular}

Data were analyzed by t-test and are presented as the mean \pm SD or n (\%). n, absolute frequency; \%, relative frequency; EG, Experimental Group; CG, Control Group; ABEP, Brazilian Marketing Research Association; MMSE, Mini-Mental State Examination; UPDRS, Unified Parkinson's Disease Rating Scale; 6MWT, 6-min Walk Test; MoCA, Montreal Cognitive Assessment.

the effect of the interval training on a cycle ergometer, there was an increase in the relative expression levels of miR-106a-5p in the EG $(\mathrm{P}=0.04)$ and no difference in the $\mathrm{CG}(\mathrm{P}=0.07)$ compared with the levels before training (Fig. 1A). There was an increase in the relative expression levels of miR-103a-3p in the $\mathrm{CG}(\mathrm{P}=0.005)$, but no significant difference was observed in the EG $(\mathrm{P}=0.09)$ after training (Fig. 1B). The expression levels of miR-29a-3p were upregulated in the $\mathrm{CG}(\mathrm{P}=0.06)$ (Fig. 1C), while no statistical difference was noted in the EG $(\mathrm{P}=0.16)$.

Correlation between relative expression levels of miRNAs, MMSE, UPDRS, MoCA and 6MWT. Spearman's rank correlation coefficient was used to identify the correlation between the analyzed variables. The cognitive profile assessed using the MMSE was moderately, positively correlated with the relative expression levels of miR-106a-5p, miR-103a-3p and miR-29a-3p (Fig. 2).

The variables UPDRS, MoCA and 6MWT were not correlated with the relative expression levels of the assessed miRNAs (Table II).

Target genes. The target genes for the three miRNAs were identified using the TargetScan and miRDB databases. Among these genes, 943 genes were predicted for miR-106a-5p, 438 genes for miR-103a-3p and 771 genes for miR-29a-3p in both databases (Fig. S1 and Data S1). The analysis of the main biological processes involved with the target genes identified an important relation with the 'Wnt signaling pathway', as well as with the development of the nervous system, bones and muscles (Fig. 3 and Table SII).
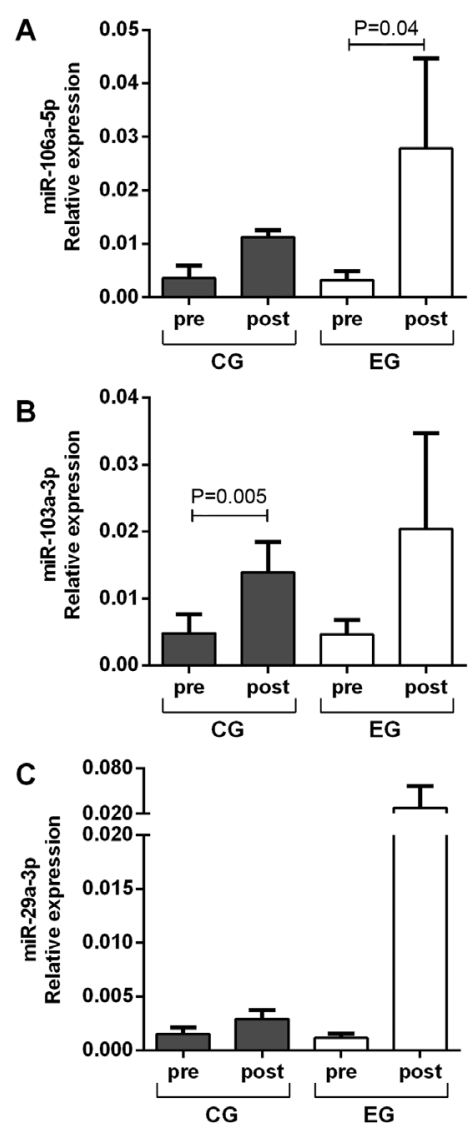

Figure 1. Relative expression levels of (A) miR-106a-5p, (B) miR-103a-3p and (C) miR-29a-3p in the CG and EG before and after interval training on a cycle ergometer. Data are presented as the mean \pm SD of relative expression. Statistical differences were calculated using the t-test for independent or paired samples. miR, microRNA; CG, control group; EG, experimental group. 
Table II. Correlation between the variables UPDRS, MoCA, 6MWT and the relative expression levels of miR-106a-5p, miR-103a-3p and miR-29a-3p.

\begin{tabular}{|c|c|c|c|c|c|c|}
\hline \multirow[b]{2}{*}{ Variables } & \multicolumn{2}{|c|}{ miR-106a-5p } & \multicolumn{2}{|c|}{ miR-103a-3p } & \multicolumn{2}{|c|}{ miR-29a-3p } \\
\hline & $\rho$ & P-value & $\rho$ & P-value & $\rho$ & P-value \\
\hline MoCA & 0.450 & 0.093 & 0.340 & 0.214 & 0.457 & 0.088 \\
\hline UPDRS & -0.234 & 0.365 & -0.248 & 0.337 & -0.304 & 0.241 \\
\hline $6 \mathrm{MWT}$ & 0.085 & 0.760 & 0.237 & 0.390 & 0.143 & 0.608 \\
\hline
\end{tabular}

Correlation was assessed using the Spearman's Rank Correlation Coefficient. MoCA, Montreal Cognitive Assessment; UPDRS, Unified Parkinson's Disease Rating Scale; 6MWT, 6-min walk test; miR, microRNA.
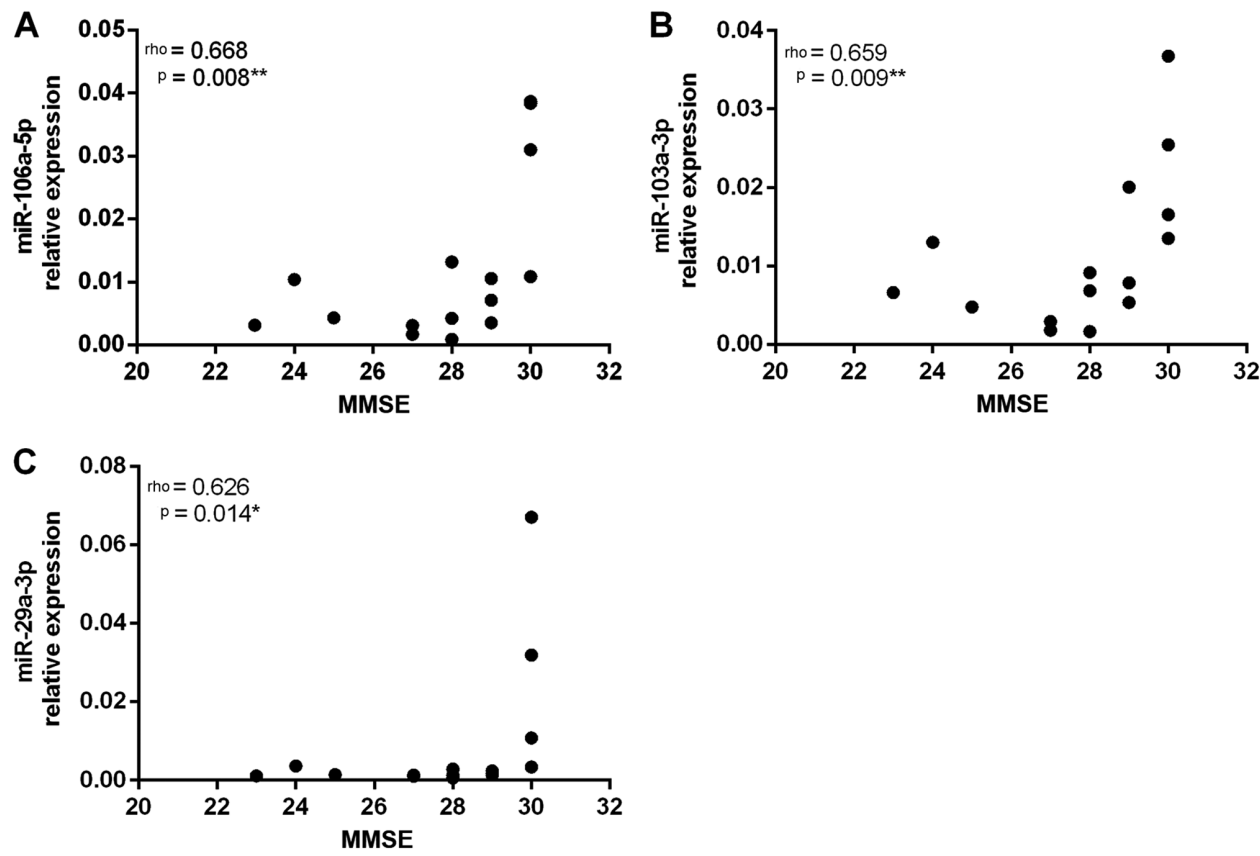

Figure 2. Correlations between the values obtained in the MMSE and the relative expression levels of (A) miR-106a-5p, (B) miR-103a-3p and (C) miR-29a-3p. The correlation was assessed using the Spearman's Rank Correlation Coefficient (r). Significant P-values are marked with an asterisk. MMSE, Mini-Mental State Examination; miR, microRNA.

\section{Discussion}

PD is the most prevalent movement disorder of the central nervous system, characterized by the progressive loss of dopaminergic neurons in the substantia nigra pars compacta and the accumulation of $\alpha$-synuclein $(10,16,20)$. The accumulation of the $\alpha$-synuclein protein leads to neuronal dysfunction. miRNAs can modulate the accumulation of this factor and other proteins by regulating the genes that encode these toxic proteins and transcription factors, or by altering the expression of proteins that regulate survival of neuronal cells (75). In this context, miRNAs are involved directly and indirectly in the pathogenesis of PD (75-79), and therefore, miRNAs that target genes involved in neurodegeneration are of potential therapeutic value (80).

In the present study, it was possible to observe an increase in relative expression levels of miR-106a-5p, miR-103a-3p and miR-29a-3p in serum of individuals who participated in a supervised cycling training program of $30 \mathrm{~min}$, three times a week for a period of 8 weeks. Notably, the program promoted a significant increase in the expression of miR-106a-5p.

In healthy individuals, previous studies have reported changes in miRNA expression levels after aerobic exercise. For instance, Denham et al (34) observed a reduction in miR-210 and an increase in miR-21 after 12 weeks of physical exercise on the treadmill. In four studies, changes were identified in 38 miRNAs in neutrophils (25), 33 miRNAs in peripheral blood mononuclear cells (26), 22 miRNAs in natural killer cells (27) and 18 in monocytes (28) in healthy men after exercise using a cycle ergometry. Another study revealed the acute and chronic effects of stationary bike exercise in healthy young individuals on the expression levels of miRNAs (46). In a previous study, miR-106a, miR-221, miR-30b, miR-151-5p, let-7i, miR-146a, miR-652 and miR-151-3p expression levels were decreased, while miR-338-3p, miR-330-3p, miR-223, miR-139-5p, miR-143, miR-145 and miR-424 expression levels were increased after $1 \mathrm{~h}$ of training. After 12 weeks, there was a decrease in miR-342-3p, let-7d, miR-766, miR-25, miR-148a, 
A miR-106a-5p-Biological process

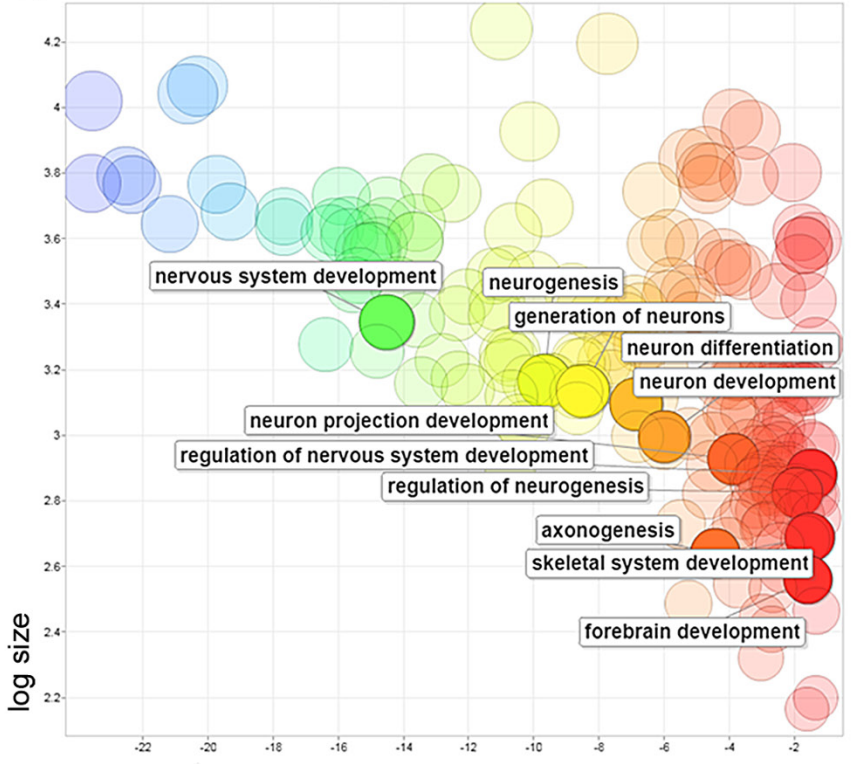

$\log 10 \mathrm{P}$-value
B miR-103a-3p - Biological process

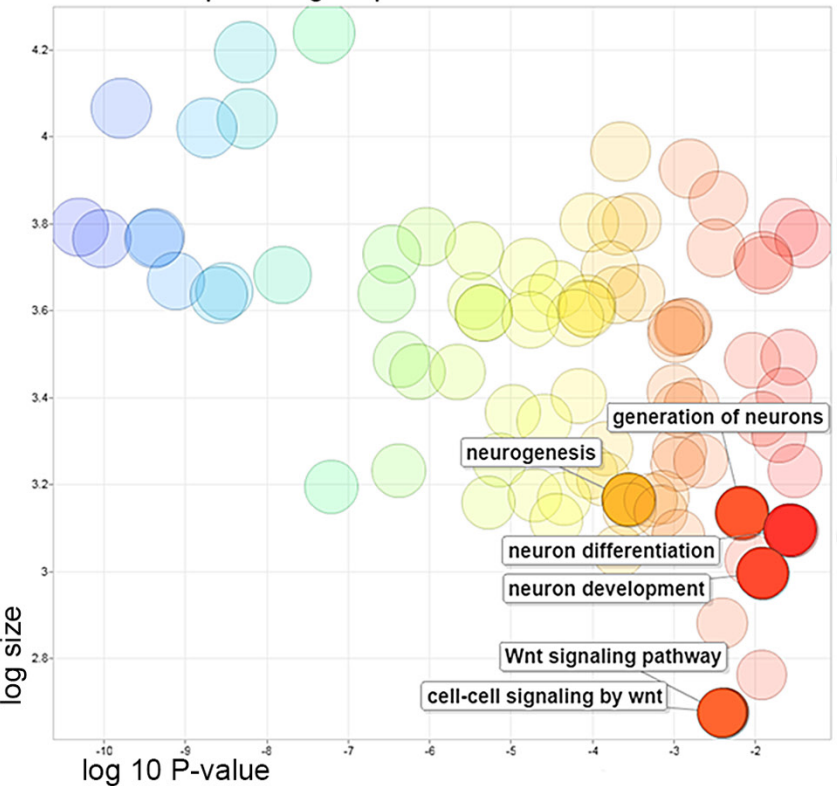

C

miR-29a-3p - Biological process

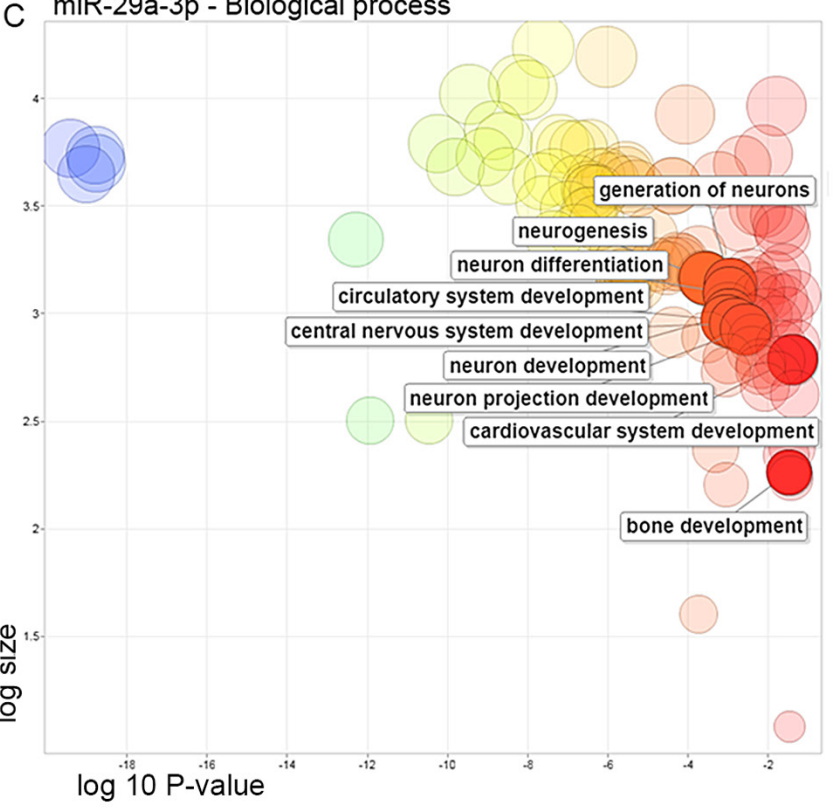

Figure 3. Ontological analysis of significant biological processes associated with Parkinson's disease regulated by the predicted target genes of (A) miR-106a-5p, (B) miR-103a-3p and (C) miR-29a-3p. miR, microRNA.

miR-185 and miR-21 expression levels and an increase in miR-103 and miR-107 expression levels (46). These results suggested the potential value of miRNAs as a possible physiological mediator of exercise-induced adaptation in healthy individuals and in individuals with neurological diseases, such as PD.

In the present study, positive correlations were observed between the MMSE values and the relative expression levels of miR-106a-5p, miR-103a-3p and miR-29a-3p, indicating that the increase in the expression level of these miRNAs was associated with decreased cognitive deficit. Other studies also reported a correlation between miR-29a expression and MMSE in patients with vascular dementia (81), and between miR-103a expression and MMSE in Japanese subjects without a clinical diagnosis of dementia who attended a health examination in Yakumo, Hokkaido (82). A study involving an ovariectomized mouse model of cognitive impairment suggested that miR-106a may be a marker of onset or a potential therapeutic target for cognitive disturbances (83). At present, to the best of our knowledge, only Serafin et al (79) demonstrated dysregulation of miR-103a-3p and miR-29a-3p in PD; additionally, overexpression in peripheral blood mononuclear cells of patients treated with L-dopa was observed.

Prediction analyses of target genes in the present study revealed that these miRNAs are associated with important biological processes involved in motor function and in the development of the central nervous system. Some of these target genes have been validated in functional experiments, where it has been reported that $\mathrm{miR}-106 \mathrm{a}-5 \mathrm{p}$ regulates the expression of the autophagy-related gene 7 (84), and suppression of this gene is associated with the death of dopaminergic 
neurons and accumulation of $\alpha$-synuclein (85). Moreover, miR-106a-5p has been reported to regulate the expression of the hypoxia-induced factor-1 gene (86), which is associated with cell death in various neurodegenerative diseases. In addition to regulating processes related to neurogenesis, miR-106a-5p serves a role in myogenesis. Recently, miR-106a-5p has been identified in animal models as a repressor of myogenesis as it inhibits differentiation and promotes atrophy by blocking the PI3K/AKT signaling pathway via PIK3R1 (87). A previous study also observed that miR-106a-5p was downregulated immediately after acute exercise in young healthy men (88); however, the impact of exercises in older men is yet to be elucidated.

Prediction analyses of target genes of miR-103a-3p have demonstrated a relationship with the Wnt signaling pathway $(89,90)$. This pathway is associated with the survival of dopaminergic neurons and their dysregulation may be a potential cause for PD $(89,90)$, suggesting that miR-103a-3p can regulate the expression of the extracellular Dickkopf-1 protein (DKK1) (88). A recent study confirmed that miR-103a-3p can regulate DKK1 expression (88). Furthermore, this protein can block the canonical Wnt pathway, contributing to neurotoxicity in PD $(91,92)$. miR-103a-3p is also involved in the regulation of several other PD-related processes, such as the regulation of myocyte enhancer factor-2 (MEF2D) transcription factor, and the regulation of MEF2D is associated with loss of dopaminergic neurons $(93,94)$. miR-103a-3p and miR-29a-3p are related to insulin resistance, a process that may be linked to neurodegeneration in DP (95-100).

In the present study, although miR-29a-3p did not show a statistically significant difference between the pre- and post-exercise groups, a correlation with cognitive profile assessed using the MMSE was noted. One of the targets of miR-29a-3p is G protein-coupled receptor 37 (GPR37) (99). The intracellular accumulation of GPR37 is neurotoxic and is associated with PD (99). Inactivation of GPR37 produces motor and non-motor phenotypes relevant to PD (99). Thus, poor regulation of GPR37 due to overexpression of miR-29a-3p may be associated with PD (79). CDC42, a candidate gene for PD involved in neuronal death (100), was also identified as a potential target for miR-29a-3p.

An emerging paradigm of post-transcriptional molecular regulation due to physical exercises involves the action of miRNAs, which regulate mRNA translation (38). Several studies have examined the acute and/or chronic effects of physical exercises s(aerobic and resistance) on various miRNAs in healthy individuals (25-36), athletes (37-40) and in young and older adults (41-50), as well as in patients with $\mathrm{CHF}(51,52)$, CKD (53), DM2 associated with morbid obesity (54), prediabetes (55) and intermittent claudication $(56,57)$. In these studies, most of the investigated subjects were men. Moreover, to the best of our knowledge, the effects of physical exercises on the expression of miRNAs in individuals with PD have not been investigated. Thus, the present study was the first to investigate the effects of an interval cycling training program on the expression levels of miRNAs in serum samples from men with PD.

In the present study, the interval cycling training program increased the expression levels of miR-106a-5p, miR-103a-3p and miR-29a-3p, with a statistically significant increase observed in the expression of miR-106a-5p. However, there is limited information regarding this miRNA in PD. The current results indicated that these miRNAs may participate in the response to exercise; however, further studies with a larger sample size are required to confirm these results. The present results suggested that miR-106a-5p, miR-103a-3p and miR-29a-3p may partially reflect exercise-induced responses or time regulation controlled by miRNAs during exercise.

Limitations of the present work are that the selected participants were only men, and that the dosage and treatment were not investigated. Therefore, future research should be performed to investigate whether this is a sex-specific issue, as well as to examine the relationship between patients were treated with L-dopa or Prolopa.

In conclusion, in men with $\mathrm{PD}$, serum expression levels of miR-106a-5p, miR-103a-3p and miR-29a-3p were increased in response to a supervised interval training program on a cycle ergometer for $30 \mathrm{~min}$, three times a week for a period of 8 weeks. It was found that the program promoted a significant increase in the expression of miR-106a-5p. Additionally, the expression levels of miR106a-5p, miR-103a-3p and miR-29a-3p were positively correlated with MMSE values. Further studies are required to clarify the potential use of these circulating miRNAs as markers of adaptation to physical exercise. The present results indicated that these three miRNAs were associated with the exercise response and cognitive improvement in men with PD.

\section{Acknowledgements}

Not applicable.

\section{Funding}

No funding was received.

\section{Availability of data and materials}

The datasets used and/or analyzed during the current study are available from the corresponding author upon reasonable request.

\section{Authors' contributions}

FCDS, MPR and RDS designed the study. FCDS, MPR, GGV, RDRI and TBCP performed the experiments. FCDS, MPR and ASM analyzed the data. FCDS and MPR prepared the manuscript. FCDS, MPR, GGV and RDRI confirmed the authenticity of all the raw data. All authors read and approved the final version of the manuscript

\section{Ethics approval and consent to participate}

This study was approved by the Ethics Committee for Research involving Human Beings of the State University of Santa Catarina, with the Certificate of Presentation for Ethical Appreciation no. 50032415.1.0000.0118, in 2015. The objectives of this study and the procedures to be adopted throughout the research were explained to all participants, who voluntarily agreed to continue participation by signing an informed consent document. 


\section{Patient consent for publication}

Not applicable.

\section{Competing interests}

The authors declare that they have no competing interests.

\section{References}

1. The World Health Organization 2017. Physical activity and adults. http://www.who.int/dietphysicalactivity/factsheet_adults/ en/. Accessed January 8, 2019.

2. Barnett A, Smith B, Lord SR, Williams M and Baumand A Community-based group exercise improves balance and reduces falls in at-risk older people: A randomised controlled trial. Age Ageing 32: 407-414, 2003.

3. Gillespie LD, Robertson MC, Gillespie WJ, Sherrington C, Gates S, Clemson LM and Lamb SE: Interventions for preventing falls in older people living in the community. Cochrane Database Syst Rev: CD007146, 2012.

4. Sherrington C, Whitney JC, Lord SR, Herbert RD, Cumming RG and Close JC: Effective exercise for the prevention of falls: A systematic review and meta-analysis. J Am Geriatr Soc 56: 2234-2243, 2008

5. Fox KR: The influence of physical activity on mental well-being. Public Health Nutr 2: 411-418, 1999.

6. Cooney GM, Dwan K, Greig CA, Lawlor DA, Rimer J, Waugh FR, McMurdo M and Mead GE: Exercise for depression. Cochrane Database Syst Rev: CD004366, 2013.

7. Latt MD, Lord SR, Morris JG and Fung VS: Clinical and physiological assessments for elucidating falls risk in Parkinson's disease. Mov Disord 24: 1280-1289, 2009.

8. Allen NE, Canning CG, Sherrington C, Lord SR, Latt MD, Close JC, O'Rourke SD, Murray SM and Fung VS: The effects of an exercise program on fall risk factors in people with Parkinson's disease: A randomized controlled trial. Mov Disord 25: 1217-1225, 2010

9. Lun V, Pullan N, Labelle N, Adams C and Suchowersky O: Comparison of the effects of a self-supervised home exercise program with a physiotherapist-supervised exercise program on the motor symptoms of Parkinson's disease. Mov Disord 20 971-975, 2005.

10. Tomlinson CL, Patel S, Meek C, Clarke CE, Stowe R, Shah L, Sackley CM, Deane KHO, Herd CP, Wheatley K and Ives N: Physiotherapy versus placebo or no intervention in Parkinson's disease. Cochrane Database Syst Rev: CD002817, 2012.

11. Goodwin VA, Richards SH, Taylor RS, Taylor AH and Campbell JL: The effectiveness of exercise interventions for people with Parkinson's disease: A systematic review and meta-analysis. Mov Disord 23: 631-640, 2008.

12. Rochester L, Nieuwboer A and Lord S: Physiotherapy for Parkinson's disease: Defining evidence within a framework for intervention. Neurodegenerative Disease Management 1: 57-65, 2011.

13. da Silva FC, Iop RDR, de Oliveira LC, Boll AM, de Alvarenga JGS Gutierres Filho PJB, de Melo LMAB, Xavier AJ and da Silva R: Effects of physical exercise programs on cognitive function in Parkinson's disease patients: A systematic review of randomized controlled trials of the last 10 years. PLoS One 13: e0193113, 2018.

14. Oguh O, Eisenstein A, Kwasny M and Simuni T: Back to the basics: Regular exercise matters in parkinson's disease: Results from the national Parkinson foundation QII registry study. Parkinsonism Relat Disord 20: 1221-1225, 2014

15. Murray DK, Sacheli MA, Eng JJ and Stoessl AJ: The effects of exercise on cognition in Parkinson's disease: A systematic review. Transl Neurodegener 3: 5, 2014.

16. Schapira AH: Neurobiology and treatment of Parkinson's disease. Trends Pharmacol Sci 30: 41-47, 2009.

17. Morris ME, Iansek R and Kirkwood B: A randomized controlled trial of movement strategies compared with exercise for people with Parkinson's disease. Mov Disord 24: 64-71, 2009.

18. van Nimwegen M, Speelman AD, Hofman-van Rossum EJ, Overeem S, Deeg DJ, Borm GF, van der Horst MH, Bloem BR and Munneke M: Physical inactivity in Parkinson's disease. J Neurol 258: 2214-2221, 2011.
19. van Hilten JJ, Hoogland G, van der Velde EA, Middelkoop HA, Kerkhof GA and Roos RA: Diurnal effects of motor activity and fatigue in Parkinson's disease. J Neurol Neurosurg Psychiatry 56: 874-877, 1993

20. Harraz MM, Dawson TM and Dawson VL: MicroRNAs in Parkinson's disease. J Chem Neuroanat 4: 127-130, 2011.

21. Mouradian MM: MicroRNAs in Parkinson's disease. Neurobiol Dis 46: 279-284, 2012.

22. Filatova EV, Alieva AKh, Shadrina MI and Slominsky PA: MicroRNAs: Possible role in pathogenesis of Parkinson's disease. Biochemistry (Mosc) 77: 813-819, 2012.

23. da Silva FC, Iop RD, Vietta GG, Kair DA, Gutierres Filho PJ, de Alvarenga JG and da Silva R: microRNAs involved in Parkinson's disease: A systematic review. Mol Med Rep 14: 4015-4022, 2016.

24. Silva FCD, Iop RDR, Andrade A, Costa VP, Gutierres Filho PJB and Silva RD: Effects of physical exercise on the expression of MicroRNAs: A Systematic review. J Strength Cond Res 34: 270-280, 2020.

25. Radom-Aizik S, Zaldivar F, Oliver S, Galassetti $P$ and Cooper DM: Effects of exercise on miRNA expression levels in human peripheral blood mononuclear cells (PBMCs). FASEB J 24: $626.4,2010$

26. Radom-Aizik S, Zaldivar F Jr, Leu SY, Adams GR, Oliver S and Cooper DM: Effects of exercise on microRNA expression in young males peripheral blood mononuclear cells. Clin Transl Sci 5: 32-38, 2012.

27. Radom-Aizik S, Zaldivar F, Haddad F and Cooper DM: Impact of brief exercise on peripheral blood NK cell gene and microRNA expression in young adults. J Appl Physiol (1985) 114: 628-636, 2013.

28. Radom-Aizik S, Zaldivar FP Jr, Haddad F and Cooper DM: Impact of brief exercise on circulating monocyte gene and microRNA expression: Implications for atherosclerotic vascular disease. Brain Behav Immun 39: 121-129, 2014.

29. Guescini M, Canonico B, Lucertini F, Maggio S, Annibalini G, Barbieri E, Luchetti F, Papa S and Stocchi V: Muscle releases alpha-sarcoglycan positive extracellular vesicles carrying miRNAs in the bloodstream. PLoS One 10: e0125094, 2015.

30. Chilton WL, Marques FZ, West J, Kannourakis G, Berzins SP, O'Brien BJ and Charchar FJ: Acute exercise leads to regulation of telomere-associated genes and microRNA expression in immune cells. PLoS One 9: e92088, 2014

31. Uhlemann M,Möbius-Winkler S, Fikenzer S, Adam J, Redlich M, Möhlenkamp S, Hilberg T, Schuler GC and Adams V: Circulating microRNA-126 increases after different forms of endurance exercise in healthy adults. Eur J Prev Cardiol 21: 484-491, 2014.

32. McLean CS, Mielke C, Cordova JM, Langlais PR, Bowen B, Miranda D, Coletta DK and Mandarino LJ: Gene and MicroRNA expression responses to exercise; relationship with insulin sensitivity. PLoS One 10: e0127089, 2015.

33. Fyfe JJ, Bishop DJ, Zacharewicz E, Russell AP and Stepto NK: Concurrent exercise incorporating high-intensity interval or continuous training modulates mTORC1 signaling and microRNA expression in human skeletal muscle. Am J Physiol Regul Integr Comp Physiol 310: R1297-R1311, 2016.

34. Denham J, O'Brien BJ, Marques FZ and Charchar FJ: Changes in the leukocyte methylome and its effect on cardiovascular-related genes after exercise. J Appl Physiol (1985) 118: 475-488, 2015.

35. Dias RG, Silva MS, Duarte NE, Bolani W, Alves CR, Lemos JR, da Silva JL, de Oliveira PA, Alves GB, de Oliveira EM, et al: PBMCs express a transcriptome signature predictor of oxygen uptake responsiveness to endurance exercise training in men. Physiol Genomics 7: 13-23, 2015.

36. Nielsen S, Scheele C, Yfanti C, Åkerström T, Nielsen AR, Pedersen BK and Laye MJ: Muscle specific microRNAs are regulated by endurance exercise in human skeletal muscle. J Physiol 588: 4029-4037, 2010.

37. Backes C, Leidinger P, Keller A, Hart M, Meyer T, Meese E and Hecksteden A: Blood born miRNAs signatures that can serve as disease specific biomarkers are not significantly affected by overall fitness and exercise. PLoS One 9: e102183, 2014.

38. Tonevitsky AG, Maltseva DV, Abbasi A, Samatov TR, Sakharov DA, Shkurnikov MU, Lebedev AE, Galatenko VV, Grigoriev AI and Northoff $\mathrm{H}$ : Dynamically regulated miRNA-mRNA networks revealed by exercise. BMC Physiol 13: 9, 2013.

39. Mooren FC, Viereck J, Kruger K and Thum T: Circulating microRNAs as potential biomarkers of aerobic exercise capacity. Am J Physiol Heart Circ Physiol 4: H557-H563, 2014. 
40. Baggish AL, Hale A, Weiner RB, Lewis GD, Systrom D, Wang F, Wang TJ and Chan SY: Dynamic regulation of circulating MicroRNA during acute exhaustive exercise and sustained aerobic exercise training. J Physiol 589: 3983-3994, 2011.

41. Cui SF, Li W, Niu J, Zhang CY, Chen X and Ma JZ: Acute responses of circulating microRNAs to low-volume sprint interval cycling. Front Physiol 6: 311, 2015.

42. Cui SF, Wang C, Yin X, Tian D, Lu QJ, Zhang CY, Chen X and Ma JZ: Similar responses of circulating microRNAs to acute high-intensity interval exercise and vigorous-intensity continuous exercise. Front Physiol 7: 102, 2016.

43. Zacharewicz E, Della Gatta P, Reynolds J, Garnham A, Crowley T, Russell AP and Lamon S: Identification of microRNAs linked to regulators of muscle protein synthesis and regeneration in young and old skeletal muscle. PLoS One 9: e114009, 2014.

44. Mueller M, Breil FA, Lurman G, Klossner S, Fluck M, Billeter R, Dapp C and Hoppeler H: Different molecular and structural adaptations with eccentric and conventional strength training in elderly men and women. Gerontology 57: 528-538, 2011.

45. Drummond MJ, McCarthy JJ, Fry CS, Esser KA and Rasmussen BB Aging differentially affects human skeletal muscle microRNA expression at rest and after an anabolic stimulus of resistance exercise and essential amino acids. Am J Physiol Endocrinol Metab 295: E1333-E1340, 2008.

46. Davidsen PK, Gallagher IJ, Hartman JW, Tarnopolsky MA, Dela F, Helge JW, Timmons JA and Phillips SM: High responders to resistance exercise training demonstrate differential regulation of skeletal muscle microRNA expression. J Appl Physio (1985) 110: 309-317, 2011.

47. Nielsen S,Hvid T, Kelly M,Lindegaard B, Dethlefsen C, Winding K, Mathur N, Scheele C, Pedersen BK and Laye MJ: Muscle specific miRNAs are induced by testosterone and independently upregulated by age. Front Physiol 4: 394, 2014.

48. Zhang T, Birbrair A, Wang ZM, Messi ML, Marsh AP, Leng I, Nicklas BJ and Delbono O: Improved knee extensor strength with resistance training associates with muscle specific miRNAs in older adults. Exp Gerontol 62: 7-13, 2015.

49. Aoi W, Ichikawa H, Mune K, Tanimura Y, Mizushima K, Naito Y and Yoshikawa T: Muscle-enriched microRNA miR-486 decreases in circulation in response to exercise in young men. Front Physiol 4: 80, 2013.

50. Margolis LM, Lessard SJ, Ezzyat Y, Fielding RA and Rivas DA Circulating MicroRNA are predictive of aging and acute adaptive response to resistance exercise in men. J Gerontol A Biol Sci Med Sci 72: 1319-1326, 2017.

51. Xu T, Liu Q, Yao J, Dai Y, Wang $\mathrm{H}$ and Xiao J: Circulating microRNAs in response to exercise. Scand J Med Sci Sports 25: e149-e154, 2015

52. Riedel S, Radzanowski S, Bowen TS, Werner S, Erbs S, Schuler G and Adams V: Exercise training improves high-density lipoprotein-mediated transcription of proangiogenic microRNA in endothelial cells. Eur J Prev Cardiol 22: 899-903, 2015.

53. Van Craenenbroeck AH,Ledeganck KJ, Van Ackeren K, Jürgens A, Hoymans VY, Fransen E, Adams V, De Winter BY, Verpooten GA, Vrints CJ, et al: Plasma levels of microRNA in chronic kidney disease: Patterns in acute and chronic exercise. Am J Physiol Heart Circ Physiol 309: H2008-H2016, 2015.

54. Rowlands DS, Page RA, Sukala WR, Giri M, Ghimbovschi SD Hayat I, Cheema BS, Lys I, Leikis M, Sheard PW, et al: Multi-omic integrated networks connect DNA methylation and miRNA with skeletal muscle plasticity to chronic exercise in Type 2 diabetic obesity. Physiol Genomics 46: 747-765, 2014.

55. Parrizas M, Brugnara L, Esteban Y, Gonzalez-Franquesa A, Canivell S, Murillo S, Gordillo-Bastidas E, Cusso R, Cadefau JA, Garcia-Roves PM, et al: Circulating miR-192 and miR-193b are markers of prediabetes and are modulated by an exercise intervention. J Clin Endocrinol Metab 100: E407-E415, 2015.

56. da Silva ND Jr, Roseguini BT, Chehuen M, Fernandes T, Mota GF, Martin PK, Han SW, Forjaz CL, Wolosker N and de Oliveira EM: Effects of oral N-acetylcysteine on walking capacity, leg reactive hyperemia, and inflammatory and angiogenic mediators in patients with intermittent claudication. Am J Physiol Heart Circ Physiol 309: H897-H905, 2015.

57. Nowak WN, Mika P, Nowobilski R, Kusinska K, BukowskaStrakova K, Nizankowski R, Józkowicz A, Szczeklik A and Dulak J: Exercise training in intermittent claudication: Effects on antioxidant genes, inflammatory mediators and proangiogenic progenitor cells. Thromb Haemost 108: 824-831, 2012.

58. Shen JJ, Wang YF and Yang W: Sex-interacting mRNA- and miRNA-eQTLs and their implications in gene expression regulation and disease. Front Genet 10: 313, 2019.
59. Sharma $S$ and Eghbali M: Influence of sex differences on microRNA gene regulation in disease. Biol Sex Differ 5: 3, 2014.

60. Hoehn MM and Yahr MD: Parkinsonism: Onset, progression and mortality. Neurology 17: 427-442, 1967

61. Fahn S and Elton R: Members of the UPDRS Development Committee. In: Recent Developments in Parkinson's Disease. Vol. 2. Fahn S, Marsden CD, Calne DB and Goldstein M (eds). Macmillan Health Care Information, Florham park, NJ. pp153-163, 293-304, 1987.

62. Folstein MF, Folstein SE and McHugh PR: 'Mini-mental state'. A practical method for grading the cognitive state of patients for the clinician. J Psychiatr Res 12: 189-198, 1975.

63. Nasreddine ZS, Phillips NA, Bédirian V, Charbonneau S, Whitehead V, Collin I, Cummings JL and Chertkow H: The montreal cognitive assessment, MoCA: A brief screening tool for mild cognitive impairment. J Am Geriatr Soc 53: 695-699, 2005.

64. Britto RR and Sousa LAP: Teste de caminhada de seis minutos-uma normatização brasileira. Fisioter Mov 19: 49-54, 2006.

65. Kobayashi E, Himuro $\mathrm{N}$ and Takahashi M: Clinical utility of the 6-min walk test for patients with moderate Parkinson's disease. Int J Rehabil Res 40: 66-70, 2017.

66. Sociedade Brasileira de Patologia Clínica/Medicina Laboratorial. Recomendações da Sociedade Brasileira de Patologia Clínica/Medicina Laboratorial para coleta de sangue venoso, 2nd edition. Minha Editora, Barueri, SP, 2010.

67. ANVISA: Agência Nacional de Vigilância Sanitária. Guia para transportes de sangue e componentes, 2013.

68. Ramakers C, Ruijter JM, Deprez RH and Moorman AF: Assumption-free analysis of quantitative real-time polymerase chain reaction (PCR) data. Neurosci Lett 339: 62-66, 2003.

69. Livak KJ and Schmittgen TD: Analysis of relative gene expression data using real-time quantitative PCR and the 2(-Delta Delta C(T)) method. Methods 25: 402-408, 2001.

70. Agarwal V, Bell GW, Nam JW and Bartel DP: Predicting effective microRNA target sites in mammalian mRNAs. Elife 4: e05005, 2015.

71. Wong $\mathrm{N}$ and Wang X: miRDB: An online resource for microRNA target prediction and functional annotations. Nucleic Acids Res 43 (Database Issue): D146-D152, 2015.

72. Ashburner M, Ball CA, Blake JA, Botstein D, Butler H, Cherry JM, Davis AP, Dolinski K, Dwight SS, Eppig JT, et al: Gene ontology: Tool for the unification of biology. The gene ontology consortium. Nat Genet 25: 25-29, 2000.

73. Supek F, Bošnjak M, Škunca N and Šmuc T: REVIGO summarizes and visualizes long lists of gene ontology terms. PLoS One 6: e21800, 2011

74. Uygur M, Bellumori M and Knight CA: Effects of a low-resistance, interval bicycling intervention in Parkinson's disease. Physiother Theory Pract 33: 897-904, 2017.

75. Eacker SM, Dawson TM and Dawson VL: Understanding microRNAs in neurodegeneration. Nat Rev Neurosci 10: 837-841, 2009.

76. Margis R, Margis R and Rieder CR: Identification of blood microRNAs associated to Parkinsonis disease. J Biotechnol 152: 96-101, 2011.

77. Martins M, Rosa A, Guedes LC, Fonseca BV, Gotovac K, Violante S, Mestre T, Coelho M, Rosa MM, Martin ER, et al: Convergence of miRNA expression profiling, $\alpha$-synuclein interacton and GWAS in Parkinson's disease. PLoS One 6: e25443, 2011.

78. Alvarez-Erviti L, Seow Y, Schapira AH, Rodriguez-Oroz MC, Obeso JA and Cooper JM: Influence of microRNA deregulation on chaperone-mediated autophagy and $\alpha$-synuclein pathology in Parkinson's disease. Cell Death Dis 4: e545, 2013.

79. Serafin A, Foco L, Zanigni S, Blankenburg H, Picard A, Zanon A, Giannini G, Pichler I, Facheris MF, Cortelli P, et al: Overexpression of blood microRNAs 103a, 30b, and 29a in L-dopa-treated patients with PD. Neurology 84: 645-653, 2015.

80. Roshan R, Ghosh T, Scaria V and Pillai B: MicroRNAs: Novel therapeutic targets in neurodegenerative diseases. Drug Discov Today 14: 1123-1129, 2009

81. Ragusa M, Bosco P, Tamburello L, Barbagallo C, Condorelli AG, Tornitore M, Spada RS, Barbagallo D, Scalia M, Elia M, et al: miRNAs plasma profiles in vascular dementia: Biomolecular data and biomedical implications. Front Cell Neurosci 10: 51, 2016.

82. Kondo M, Yamada H, Munetsuna E, Yamazaki M, Hatta T, Iwahara A, Ohashi K, Ishikawa H, Tsuboi Y, Inoue T, et al: Associations of serum microRNA-20a, -27a, and -103a with cognitive function in a Japanese population: The Yakumo study. Arch Gerontol Geriatr 82: 155-160, 2019. 
83. Zhang M, Ye Y, Cong J, Pu D, Liu J, Hu G and Wu J: Regulation of STAT3 by miR-106a is linked to cognitive impairment in ovariectomized mice. Brain Res 1503: 43-52, 2013.

84. Hao H, Xia G, Wang C, Zhong F, Liu L and Zhang D: miR-106a suppresses tumor cells death in colorectal cancer through targeting ATG7. Med Mol Morphol 50: 76-85, 2017.

85. Ahmed I, Liang Y, Schools S, Dawson VL, Dawson TM and Savitt JM: Development and characterization of a new Parkinson's disease model resulting from impaired autophagy. J Neurosci 32: 16503-16509, 2012.

86. Liu Y, Zhang J, Sun X and Li M: EMMPRIN Down-regulating miR-106a/b modifies breast cancer stem-like cell properties via interaction with fibroblasts through STAT3 and HIF-1 $\alpha$. Sci Rep 6: 28329, 2016.

87. Li X, Zhu Y, Zhang H, Ma G, Wu G, Xiang A, Shi X, Yang GS and Sun S: MicroRNA-106a-5p Inhibited C2C12 myogenesis via targeting PIK3R1 and modulating the PI3K/AKT signaling. Genes (Basel) 9: 333, 2018.

88. Nielsen S, Ákerström T, Rinnov A, Yfanti C, Scheele C, Pedersen BK and Laye MJ: The miRNA plasma signature in response to acute aerobic exercise and endurance training. PLoS One 9: e87308, 2014.

89. Berwick DC and Harvey K: The importance of Wnt signalling for neurodegeneration in Parkinson's disease. Biochem Soc Trans 40: 1123-1128, 2012.

90. Stephano F, Nolte S, Hoffmann J, El-Kholy S, von Frieling J, Bruchhaus I, Fink C and Roeder T: Impaired Wnt signaling in dopamine containing neurons is associated with pathogenesis in a rotenone triggered Drosophila Parkinson's disease model. Sci Rep 8: 2372, 2018.

91. Liu J, Wu M, Feng G, Li R, Wang Y and Jiao J: Downregulation of LINC00707 promotes osteogenic differentiation of human bone marrow-derived mesenchymal stem cells by regulating DKK1 via targeting miR-103a-3p. Int J Mol Med 46: 1029-1038, 2020.

92. Dun Y, Yang Y, Xiong Z, Feng M, Zhang Y, Wang M, Xiang J, Li G and Ma R: Induction of dickkopf-1 contributes to the neurotoxicity of $\mathrm{MPP}^{+}$in PC12 cells via inhibition of the canonical Wnt signaling pathway. Neuropharmacology 67: 168-175, 2013.
93. Scott EL and Brann DW: Estrogen regulation of Dkk1 and $\mathrm{Wnt} / \beta$-catenin signaling in neurodegenerative disease. Brain Res 1514: 63-74, 2013.

94. Li M, Liu Z, Zhang Z, Liu G, Sun S and Sun C: miR-103 promotes 3T3-L1 cell adipogenesis through AKT/mTOR signal pathway with its target being MEF2D. Biol Chem 396: 235-244, 2015.

95. Gao L, She H, Li W, Zeng J, Zhu J, Jones DP, Mao Z, Gao G and Yang Q: Oxidation of survival factor MEF2D in neuronal death and Parkinson's disease. Antioxid Redox Signal 20: 2936-2948, 2014.

96. Herrera BM, Lockstone HE, Taylor JM, Ria M, Barrett A, Collins S, Kaisaki P, Argoud K, Fernandez C, Travers ME, et al: Global microRNA expression profiles in insulin target tissues in a spontaneous rat model of type 2 diabetes. Diabetologia 53: 1099-1109, 2010.

97. Trajkovski M, Hausser J, Soutschek J, Bhat B, Akin A, Zavolan M, Heim MH and Stoffel M: MicroRNAs 103 and 107 regulate insulin sensitivity. Nature 474: 649-653, 2011.

98. Aviles-Olmos I, Limousin P, Lees A and Foltynie T: Parkinson's disease, insulin resistance and novel agents of neuroprotection. Brain 136: 374-384, 2013.

99. Mandillo S, Golini E, Marazziti D, Di Pietro C, Matteoni R and Tocchini-Valentini GP: Mice lacking the Parkinson's related GPR37/PAEL receptor show non-motor behavioral phenotypes: Age and gender effect. Genes Brain Behav 12: 465-477, 2013.

100. Karic A, Terzic R, Karic A and Peterlin B: Identifying candidate genes for Parkinson's disease by integrative genomics method. Biochem Med (Zagreb) 21: 174-181, 2011.

This work is licensed under a Creative Commons Attribution-NonCommercial-NoDerivatives 4.0 International (CC BY-NC-ND 4.0) License. 